\title{
Aplicações práticas no Ensino de Geografia: uma investigação da mobilidade urbana na cidade de João Pessoa/ PB
}

\author{
Practical applications in Geography Teaching: an investigation of urban mobility in the city \\ of João Pessoa / PB
}

SANTOS $^{1}$, C. L.; MEDEIROS ${ }^{2}$, T. D. S.

caiolimageo@gmail.com;

\begin{abstract}
Resumo
O presente artigo relata uma atividade prática aplicada ao ensino de geografia desenvolvida junto à turma do $2^{\circ}$ ano do ensino médio, da Escola Estadual Papa Paulo VI, localizada na cidade de João Pessoa - PB. A referida atividade pedagógica utilizou fatos do cotidiano social dos alunos, nesse caso, os problemas relacionados à mobilidade urbana, como objeto de pesquisa a ser desenvolvida por eles no processo de ensinoaprendizagem. A aplicação da pesquisa como método de ensino de geografia mostrou-se ser um percurso promissor no que se refere a maior participação dos educandos no desenvolvimento das atividades, ao processo de ensino-aprendizagem centralizado no aluno e o destaque da figura do professor como mediador. Desse modo, o presente artigo tem como objetivo apresentar os resultados alcançados na presente pesquisa como método eficiente para o ensino de geografia no nível médio, destacando suas potencialidades e possibilidades a partir da experiência vivenciada no desenvolvimento da prática docente.
\end{abstract}

Palavras-chave: Pesquisa, Ensino de Geografia, Práticas de Ensino.

\begin{abstract}
This article reports a practical activity applied to the teaching of geography developed in the second year of high school, at the State School of Papa Paulo VI, located in the city of João Pessoa - PB. The mentioned pedagogical activity used facts of the social daily of the students, in the case the problems related to the urban mobility, like object of research to be developed by them in the teaching-learning process. The application of the research as a method of teaching geography has been shown to be a promising route in terms of the greater participation of students in the development of activities, the teaching-learning process centralized in the student and the highlighting of the figure of the teacher as mediator. Thus, the present article aims to present "research" as an efficient method for the teaching of geography in high school, highlighting its potentialities and possibilities from the experience experienced in the development of teaching practice.
\end{abstract}

Keywords: Research, Geography Teaching, Teaching Practices.

\section{INTRODUÇÃO}

Ensinar Geografia nos dias atuais tem sido muito mais do que decorar e realizar leituras de livros didáticos. Existem vários recursos para incrementar uma aula, torná-la mais dinâmica, participativa, mais fácil de debater temáticas, enfim, transformar uma aula de Geografia mais atrativa para os alunos. Também existe a inserção do mundo digital no ambiente escolar o que consiste em um grande aparato na vivência dos estudantes. Logo, é notório que, atualmente, os docentes de Geografia enfrentam vários desafios durante a execução de suas aulas, pois precisam tirar a previsão de uma disciplina decorativa e que não possui nenhum fim beneficiário para a população ou para o cotidiano. 
As correntes pedagógicas contemporâneas propõem a centralização do processo de ensinoaprendizagem na figura no aluno (MIZUKAMI, 1986). Todavia, o papel do professor não fica relegado a segundo plano. Este, por sua vez é responsável mediação do encontro/confronto entre o sujeito (aluno) e o objeto de seu conhecimento (conteúdo escolar). Nessa perspectiva, o ensino deve ser voltado para a formação de conceitos e não uma apresentação de conceitos por parte do professor (CAVALCANTI, 2005). Conforme a mesma autora, a partir da perspectiva de Vygotsky, o conhecimento é uma produção social que emerge da atividade humana, que por sua vez, é responsável pela transformação da natureza e a constitui em objeto de conhecimento (produção cultural), e ao mesmo tempo transforma o homem em sujeito de conhecimento.

Para Almeida (2015), a prática de ensino de Geografia deve ser norteada a partir da seguinte indagação: o que ensinar e como ensinar Geografia? A referida autora propõe como método de ensino o conhecimento geográfico pela observação, por exemplo: a diferenciação das diferentes tonalidades de cores de um solo, ou organização urbana de um a cidade, observados em atividades de campo ou através de fotos. A partir da observação o aluno deve ser levado a estabelecer comparações, relacionando elementos de diversas ordens. Numa etapa mais avançada o aluno deverá realizar uma análise dos fatos e fenômenos, sendo necessário, para tanto, tomar conhecimento de modelos teóricos, para, por fim, realizar síntese dos fatos analisados.

O desenvolvimento desse trabalho pode se dar através de projetos, estudos do meio, reportagens e entrevistas. Por fim, o aluno deverá expressar o conteúdo trabalhado através de depoimentos (escritos ou orais), encenação artísticas das diversas ordens, encenação, aprofundar o conhecimento através da leitura, debates e pesquisas (ALMEIDA, 2015).

No que se refere ao auxílio tecnológico para o desenvolvimento de práticas de ensino, a geografia encontra excelentes ferramentas nas geotecnologias e na cartografia. Conforme os parâmetros curriculares nacionais (PCN) para a Geografia, além da linguagem verbal, escrita e oral, a linguagem gráfica/cartográfica é necessária para que os fenômenos geográficos sejam espacializados com localização e extensão precisas. É de fundamental importância estabelecer relação com os fenômenos e o local de ocorrência (BRASIL, 1997).

A Cartografia deve ser entendida não apenas como mais um conteúdo escolar exposto em sala de aula, mas sim, como uma excelente ferramenta de estudo aplicado aos diversos conteúdos que compõe a grade curricular referente ao Ensino da Geografia no ensino básico. No âmbito escolar, a Cartografia deve visar a leitura e interpretação de documentos cartográficos que representem a realidade vivida (CERQUEIRA; NASCIMENTO, 2013).

O Ensino de Geografia se torna mais significativo quando se utiliza da linguagem cartográfica, uma vez que possibilita a leitura do espaço a partir de representações gráficas do 
espaço vivido, tornando o conhecimento geográfico mais significativo para as crianças (CALLAI, 2005; MEDEIROS, 2010).

Conforme as orientações curriculares para o Ensino Médio, cabe à Geografia dar ao aluno competências que permitam a análise da realidade seja através da pesquisa e do entendimento de causa e efeito das ações humanas sobre a natureza. Ferretti (2014) afirma que o atual entendimento do objeto da Geografia, como está sendo aprendido e ensinado nas Universidades, e como previsto nos PCN e Orientação Curriculares, exige que a disciplina da Geografia Escolar seja teórico-prática, definida assim por uma experimentação que deve se dar inicialmente no estudo do lugar, a fim de que se possa experienciar os elementos da paisagem.

As orientações curriculares para o Ensino Médio, para Geografia, definem que o ensino básico "deve preparar o aluno para: localizar, compreender e atuar no mundo complexo, problematizar a realidade, formular proposições, reconhecer as dinâmicas existentes no espaço geográfico, pensar e atuar criticamente em sua realidade tendo em vista a sua transformação" (BRASIL; 2006; p. 43).

Com base nessa perspectiva, foi proposto à turma do $2^{\circ}$ ano do ensino médio, da Escola Estadual Papa Paulo VI, localizada no bairro de Cruz das Armas, uma atividade de investigação sobre a mobilidade urbana na cidade de João Pessoa, estado da Paraíba, cidade a qual está localizada a escola onde esse estudo foi realizado. Essa pesquisa surgiu a partir de debates em sala de aula sobre a insatisfação no uso dos transportes públicos. Logo, buscou-se saber como era o funcionamento desses transportes na cidade; realmente existia uma insatisfação? Se sim, qual seria a maior causa? Existe alguma solução possível? O que foi proposto pelos estudantes?

$\mathrm{O}$ assunto vem junto às discussões sobre a temática urbanização, onde, trazendo para o contexto de vivência dos estudantes, começa-se a mostrar o espaço urbano de João Pessoa em sua formação e desenvolvimento. Como se pode ver o centro urbano se desenvolve, mas nem todos os seus serviços acompanham tal desenvolvimento, chegando a um exemplo prático para todos os alunos da turma; o transporte público.

Desse modo, o presente trabalho tem como objetivo, apresentar a "pesquisa" como método eficiente para o ensino de geografia no ensino médio, destacando suas potencialidades e possibilidades a partir da experiência vivenciada no desenvolvimento da prática docente.

\section{METODOLOGIA}

A atividade consiste basicamente em aplicar a prática da pesquisa a situações cotidianas aos educandos. Na ocasião foi proposto o tema "mobilidade urbana" para o desenvolvimento da pesquisa. 
Saviani (1984) considera a pesquisa um caminhar sobre o desconhecido, e seus resultados representam o confronto com o conhecido. Desse modo, não é possível realizar pesquisa sem conhecimento prévio da área do conhecimento da que se pretende pesquisar, sem compreender seus conceitos, fundamentos científicos e orientações metodológicas.

Partido dessa premissa, no desenvolvimento das atividades, os educandos foram orientados a embasar teoricamente o seu respectivo tema através da leitura do material didático disponibilizado. Foi analisado o desenvolvimento do processo de urbanização em países subdesenvolvidos e/ou emergentes, apontando os diversos problemas observados nas grandes cidades desses países, adentrando, desse modo, no conteúdo escolar: urbanização, fazendo correlação desse contexto geral descrito com o contexto urbano/social vivenciado por eles.

Em seguida, os educandos foram orientados a investigar os problemas relacionados a mobilidade urbana, especificamente os problemas relacionados ao transporte público observados na cidade de João Pessoa/PB.

Desse modo, a pesquisa desenvolvida pelos alunos se desenvolveu nas seguintes etapas:

I. Consulta a dados oficiais referentes ao contingente populacional dos seguintes bairros: Bairro das Indústrias e Jardim Veneza, localizados na zona oeste do município de João Pessoa, disponibilizados pela secretaria de planejamento do referido município;

II. Consulta a SEMOB (Secretaria de Mobilidade Urbana) do município de João Pessoa, a fim de verificar o quantitativo de veículos, número de viagens e os horários dos coletivos que atendem a população dos referidos bairros;

III. Pesquisa de satisfação junto aos passageiros usuários do serviço de transporte público nos referidos bairros, mediante aplicação de questionário no momento em que os estudantes (pesquisadores) estavam se transportando para a escola, tendo em vista que todos habitavam nos respectivos bairros pesquisados;

IV. Compilação e discussão dos dados obtidos;

V. Elaboração do manuscrito;

VI. Apresentação da pesquisa.

Em linhas gerais, a atividade se desenvolveu nas seguintes etapas: embasamento teórico por meio da pesquisa bibliográfica; pesquisa de campo a partir da consulta de dados oficiais e pesquisa de satisfação junto aos usuários do transporte público na área pesquisada; elaboração de manuscrito contendo os dados da pesquisa e discussão do problema abordada; e por fim, a apresentação dos resultados da pesquisa. 
Todas as etapas foram acompanhadas e orientadas pelo professor regente, sendo possível verificar as principais dificuldades e potencialidades dos educandos e orienta-los quanto a melhor forma de executar os passos da pesquisa.

Como forma de avaliação das atividades propostas, os educandos foram orientados a produzir um pequeno relatório, abordando os conhecimentos adquiridos, as impressões e suas propostas para solução dos problemas apresentados.

\section{RESULTADOS E DISCUSSÃO}

A análise dos dados referentes ao censo demográfico dos anos 2000 e 2010, conforme o IBGE, demostrou que nos últimos anos a população dos bairros analisados (Bairro das Indústrias e Jardim Veneza) tem aumentado num ritmo acelerado. No ano 2000 o número total de habitantes do município de João Pessoa representava um total de 597.934 habitantes. Em 2010 esse número aumentou para 723.515 habitantes, representando um aumento de $24,17 \%$ em relação ao senso anterior. Com base no senso de 2010, o número de habitantes dos bairros pesquisados corresponde a 12.812 habitantes no Jardim Veneza e 16.638 habitantes no Bairro das Indústrias, conforme tabela 01.

Tabela 01: Dados demográficos do município de João Pessoa com base nos censos de 2000 e 2010. Fonte: IBGE.

\begin{tabular}{|c|c|}
\hline \multicolumn{2}{|c|}{ POPULAÇÃO MÉDIA DO MUNICÍPIO DE JOÃO PESSOA/PB } \\
\hline CENSO DEMOGRÁFICO/ANO (2000) & 597,934 hab. \\
\hline CENSO DEMOGRÁFICO/ANO (2010) & 723,515 hab. \\
\hline CRESCIMENTO MÉDIO & $24,17 \%$ \\
\hline
\end{tabular}

A partir de então, foi analisado juntamente com os alunos, no decorrer das aulas, que esse crescimento populacional se deveu à criação de loteamentos no período analisado, sobretudo no Bairro das Indústrias, bem como por conta da implantação de programas habitacionais por parte do governo federal, resultando na criação de diversos prédios habitacionais nos referidos bairro com uma capacidade de abrigar em média 1.788 famílias, segundo dados publicados pela Secretaria de Mobilidade Urbana de João Pessoa, atraindo diversas pessoas de todas as partes da cidade de João Pessoa. 
Em contrapartida, a quantidade veículos disponibilizados para o transporte público dessa população, que em sua maioria se desloca diariamente para as regiões centrais da cidade, tanto para trabalhar quanto para estudar, não cresceu na mesma proporção, comprometendo a qualidade dos serviços prestados, ou seja, recorrentemente, sobretudo nos horários de pico, observa-se a superlotação dos coletivos, gerando desconforto para os passageiros, além do aumento do tempo de espera na parada de ônibus, pois em muitos casos a superlotação dos veículos impede a entrada de novos passageiros. O quantitativo de veículos de transporte público que atendem os referidos bairros corresponde a um número total de 16 veículos nos dias úteis, 12 aos sábados e 08 aos domingos, divididos em duas linhas com distintos itinerários (104 e 1001), conforme a tabela 02. Desse modo, foi constatado que o número de veículos disponibilizado para atender a população desses bairros não corresponde a sua necessidade, resultando na má prestação desse serviço.

Tabela 02: Total de veículos que atendem os bairros Indústrias e Jardim Veneza. Fonte: SEMOB/João Pessoa.

\begin{tabular}{|c|ccc|}
\hline LINHA & DIAS ÚTEIS & SÁBADOS & DOMINGOS/FERIADOS \\
\hline $\mathbf{1 0 4}$ & 11 & 08 & 06 \\
$\mathbf{1 0 0 1}$ & 05 & 04 & 02 \\
\hline TOTAL & 16 & 12 & 08 \\
\hline
\end{tabular}

Outro fato constatado na pesquisa consiste no aumento de veículos de transporte clandestino, como forma de suprir as carências do transporte público. Esse tipo de transporte utiliza veículos de passeio, na maioria das vezes, em estado elevado de depreciação, sem condições legais e mecânicas de estarem em circulação. A partir dessa constatação, outro aspecto entrou na discussão realizada pelos alunos: o aumento do emprego informal. A presença massiva do transporte clandestino é resultado, sobretudo, da conjugação de dois fatores: a má prestação do serviço de transporte público e o elevado número de pessoas desempregadas.

Essa situação é vivenciada pelos educandos diariamente, isso porque, grande parte dos estudantes da escola residem nesses bairros e dependem do transporte público para se transportar.

Mediante esse quadro, a pesquisa de satisfação realizada juntos aos passageiros nas paradas de ônibus não poderiam indicar outro resultado, a não ser a de imensa insatisfação com os serviços prestados pelas empresas de transporte público.

Por fim, os resultados foram apresentados para o restante da turma e seus problemas foram debatidos de forma democrática, havendo espaço para a fala de todos, onde foi possível apresentar e 
acrescentar outros aspectos relacionados ao tema, como a margem de lucro das empresas. Para tanto, os educandos aplicaram métodos matemáticos, calculando a média diária de passageiros por veículo, multiplicada pelo valor das pesagens e o número de viagens realizadas diariamente. Além desse aspecto, também foram debatidos os problemas relacionados a violência das grandes cidades, sobretudo a vulnerabilidade a assaltos por parte dos usuários, potencializada pelo elevado tempo de espera nas paradas de ônibus.

$\mathrm{Na}$ avaliação proposta, onde os alunos desenvolveram um relatório descrevendo os conhecimentos adquiridos e suas respectivas propostas para a resolução do problema abordado, foi possível verificar uma maior compreensão do conteúdo escolar proposto, além de uma maior interação dos alunos com a atividade, uma vez que, o objeto de pesquisa era exatamente o contexto social vivenciado por ele.

A partir da análise da situação local os educandos puderam estabelecer relação com a situação do sistema de transporte públicos de outros centros urbanos que se desenvolveram num mesmo contexto histórico e econômico que o de João Pessoa, de modo que a apropriação do conhecimento se deu a partir de uma situação prática, vivenciada no dia-a-dia, porém, analisada de uma ótica científica, embasada teoricamente, não apenas baseada em impressões empíricas do senso comum.

Desse modo, a atividade se desenvolveu a partir dos princípios da pesquisa bibliográfica e de campo (embasamento teórico-científico e análise da situação), comparação com outros contextos similares, redação do texto (descrição dos dados), apresentação dos resultados obtidos (seminário), discussão com outros indivíduos na comunidade escolar e relato das impressões (relatório final).

\subsection{AVALIAÇÃO}

O procedimento avaliativo da atividade se deu de forma contínua, acompanhando o desenvolvimento de cada etapa proposta para elaboração do trabalho de pesquisa, analisando o envolvimento do aluno nas atividades propostas, seu desenvolvimento, bem como na apresentação dos resultados (apresentação oral da pesquisa). Em seguida, foi solicitado a elaboração de um relatório, descrevendo suas impressões, seu aprendizado e suas perspectivas. Abaixo segue relatos da aluna Gerlane Silva, $2^{\circ}$ ano médio, moradora do bairro Jardim Veneza, uma das áreas estudadas na pesquisa:

Como a maioria dos trabalhos escolares, não tinha um vasto conhecimento sobre o tema, mas ao pesquisar pude compreender e me posicionar como indivíduo que representa a população que utiliza o transporte público. $O$ tema despertou algo a 
mais do que uma simples pesquisa, queria compartilhar com meus colegas tudo que aprendi sobre o tema. O meu grupo colheu dados e explorou tudo que o tema nos propôs. De maneira individual, fiz uma pesquisa em campo na minha comunidade (Jardim Veneza) e adjacentes, para saber a opinião da população que utiliza diariamente o transporte público. Além disso, inclui um vídeo para confirmar tudo que foi apresentado. Durante todo esse processo, o professor Caio Lima nos deu a base e incentivo para dar o nosso melhor. E afirmo que em todos os anos de estudo, esse foi o primeiro tema que senti evolução pessoal e total segurança para apresentar com a certeza de que todos meus colegas iriam aprender.

A partir do relato da aluna citada e do forte envolvimento dos demais no desenvolvimento do trabalho, percebeu-se que a atividade prática de pesquisa envolvendo fatos relacionados ao cotidiano dos educandos deu-lhes maior motivação para realizar as atividades propostas e na busca por novos conhecimentos.

Também foi perceptível a curiosidade aguçada dos alunos, característica típica de um bom pesquisador. Essa situação se revelava nas palavras e ideias proferidas no momento das apresentações, na busca por novas informações e na tentativa de compreender o contexto social o qual está inserido.

\section{CONSIDERAÇÕES FINAIS}

A introdução da pesquisa como método de ensino de Geografia no ensino básico demostrou ser um procedimento extremamente valioso, sobretudo quando o tema a ser pesquisado está ligado ao cotidiano do educando.

Observou-se no transcorrer da atividade um maior engajamento e aplicação dos estudantes na realização do trabalho, acompanhado de uma curiosidade mais aguçada, desejosa por soluções para os problemas vivenciados cotidianamente. Outro aspecto positivo relaciona-se a possibilidade de participação de um número maior de estudantes nas atividades, pois não se faz necessário disponibilizar de grandes recursos econômicos para sua realização, e por se tratar de uma atividade diferenciada e pratica eles se interessam mais em realiza-la.

A atividade de pesquisa também apresenta um forte potencial para o desenvolvimento do hábito da leitura, sabendo que a construção de uma pesquisa exige embasamento teórico e conceitual, obrigando o pesquisador a realizar diversas leituras consultivas em livros didáticos, sites especializados, banco de dados públicos, etc. além de libertar o cidadão da análise de fatos de forma empírica, baseado no senso comum, sem qualquer comprovação de sua veracidade.

Por fim indicamos a possibilidade de integração dessa atividade com outras componentes curriculares que compõem o currículo escolar nos diversos estabelecimentos de ensino, pois a 
construção do conhecimento geográfico recebe auxílio de diversos ramos do saber científico, além de que os diversos elementos que compõe os fenômenos observados no espaço geográficos não acorrem de modo isolado, desvinculado do mundo real.

Desse modo, apontamos os seguintes aspectos relevantes quanto a aplicação do método de pesquisa para o ensino de geografia:

- Protagonismo de aluno quanto a produção do conhecimento;

- Envolvimento do professor com o contexto socioambiental dos educandos;

- Interdicisplinaridade e transdisciplinaridade dos conteúdos escolares;

- Desenvolvimento do hábito da leitura;

- Quebra da rotina escolar, permitindo aos educandos vivenciar outros espaços de conhecimento, dentre outros aspectos.

Abordar por meio da prática da pesquisa temas relevantes ao seu contexto social permitir aos estudantes problematizar e reconhecer dinâmicas presentes em seus espaços vividos com um olhar científico, ainda mais quando se trata de um problema abrangente a uma parcela considerável da população, como o caso abordado nessa pesquisa.

\section{REFERÊNCIAS}

ALMEIDA, R. D. A propósito da questão teórico-metodológica sobre o ensino de Geografia. Terra Livre, n. 8, 2015.

BRASIL. Parâmetros curriculares nacionais: introdução aos parâmetros curriculares nacionais. Brasília: MEC Secretaria de Educação Fundamental, 1997.

BRASIL. Orientações curriculares para o ensino médio: ciências humanas e suas tecnologias. Secretaria de Educação Básica. Brasília: Ministério da Educação, Secretaria de Educação Básica, 2006.

CALLAI, H. C. Aprendendo a ler o mundo: a geografia nos anos iniciais do ensino fundamental. Cad. Cedes, Campinas, v. 25, n. 66, p. 227-247, 2005.

CAVALCANTI, L.S. Cotidiano, mediação pedagógica e formação de conceitos: uma contribuição de Vygotsky ao ensino de geografia. Cadernos Cedes, Campinas, v. 25, n. 66, p. 185-207, maio/ago. 2005.

CERQUEIRA, E. C; NASCIMENTO, D. M. C. O lugar da cartografia no ensino de geografia: perspectivas a partir de um projeto de extensão. GeoTextos, v. 9, n. 1, 2013.

FERRETTI, O. A representação do espaço geográfico na educação básica. PESQUISAR-Revista de Estudos e Pesquisas em Ensino de Geografia, v. 1, n. 1, p. 261-281, 2014.

MEDEIROS, P. C. Fundamentos teóricos e práticos do ensino de geografia. IESDE BRASIL SA, 2010. 
MIZUKAMI, M. G. N. Ensino: as abordagens do processo. São Paulo: Editora Pedagógica e Universitária, 1986.

SAVIANI, D. Escola e democracia. São Paulo: Cortez / Autores associados, 1984.

SEMOB. Secretaria de mobilidade Urbana de João Pessoa. Ações, programas e projetos de mobilidade urbana. em http://www.joaopessoa.pb.gov.br/secretarias/semob/mobilidade-urbana $>$ acesso em 23 de julho de 2016.

IBGE. Instituto Brasileiro de Geografia e Estatística. Características da População e dos Domicílios. Rio de Janeiro, 2000.

IBGE. Instituto Brasileiro de Geografia e Estatística. Características da População e dos Domicílios. Rio de Janeiro, 2010.

Recebido em: 29/05/2018

Aceito para publicação em: 29/07/2018 